\title{
Why Singaporean 8th Grade Students Gain Highest Mathematics Ranking in TIMSS (1999-2011)
}

\author{
Abdolreza Lessani ${ }^{1}$, Aida Suraya Md Yunus ${ }^{1}$, Rohani Ahmad Tarmiz ${ }^{1} \&$ Rosnaini Mahmud $^{1}$ \\ ${ }^{1}$ Faculty of Educational Studies, Univesiti Putra Malaysia, Serdang, Selangor, Malaysia \\ Correspondence: Abdolreza Lessani, Faculty of Education, Univesiti Putra Malaysia, 43400 Serdang, Selangor, \\ Malaysia. Tel: 601-3259-3609. E-mail: reza.lessani2012@gmail.com
}

Received: August 12, 2014

Accepted: September 15, 2014 Online Published: October 29, 2014

doi:10.5539/ies.v7n11p173

URL: http://dx.doi.org/10.5539/ies.v7n11p173

\begin{abstract}
The international comparison of students' mathematics knowledge and competencies is an effective method of evaluating students' mathematics performance and developing policies to improve their achievements in mathematics. Trends in International Mathematics and Science Study (TIMSS) are among the most well-recognized international comparisons that provide valuable information about students' mathematics achievement in an international area. The results of TIMSS in the period of 1999 to 2011 in students' mathematics achievement, particularly in $8^{\text {th }}$ grade, shows that Singapore has had one of the best students' mathematics achievement. The present study, therefore, deeply analyzes the mathematics curriculum, and compare the mathematics textbooks (Secondary $1 \& 2$ ) with contents domain of TIMSS including Numbers, Algebra, Geometry, and Data and Chance (Statistics and Probability), to highlight the reasons for such a desirable mathematics achievement. Findings of the present study may offer valuable insights to mathematics educators and syllabus designers.
\end{abstract}

Keywords: mathematics, student's achievement, Singapore, secondary school, content domain, TIMSS, curriculum

\section{Introduction}

Mathematics became the driving force for almost all technological and scientific developments in the 19th and 20th centuries. Scientific and mathematical models and their transformation into technology had significant influences on natural, economies, and social sciences. They also had large impact on all activities in the professional, social and daily life (Maasz \& Schloeglmann, 2006). Mathematics education has always been considered as an important component of general education and specifically science education. In order to evaluate students' performance and to develop policies to improve their achievements in science and mathematics at different levels of education, it is relevant to compare their knowledge and competencies in a specific area with students of the other countries. One such evaluation is conducted by Trends in International Mathematics and Science Study (TIMSS). The achievements, improvements, and success or failure in the international mathematics education is being reported in the TIMSS, conducted by the International Association for the Evaluation of Educational Achievement (IEA) (Gonzales et al., 2004). Due to the universal importance of mathematics education, countries are very interested in comparing their practices and achievements to those of other countries. Guangzhong (1996) stated that since the 1960s, concern on cross-national comparative studies in education has increased following the first TIMSS evaluation. Since mathematics has substantial roles in the secondary school curriculum of all countries, and because its symbolism and notation system are 'recognized world-wide" "it has attracted the most attention in those international studies compared with other areas of curricula" (Guangzhong, 1996, p. 29).

IEA has conducted a research investigating mathematics achievement in the final year of secondary school across 12 countries in the 1960s. In the 1980s, IEA undertook the Second International Mathematics Study (SIMS), in which 20 countries participated. They later conducted the TIMSS in 41 countries in 1995 (Kawanaka, 2000). In the first three assessments of mathematics education that was held by IEA, it was named as follows: FIMS (1960s), SIMS (1980s) and TIMSS (1995). After that, it has always been named as TIMSS and evaluation conducted in three level, grades $4^{\text {th }}, 8^{\text {th }}$, and advance for pre-university.

Nowadays TIMSS as an international comparative study has attracted an influential audience in many countries 
(Mills \& Holloway, 2013). This comparative study is being carried out to offer insight into students' achievement that will support reflection on a country's own system and practice (Nixon \& Barth, 2014). TIMSS in effect establishes reliable and valid scores for achievement that can be compared across countries or across groups of students within countries, and relates achievement to various background and context variables (Chudgar et al., 2013). Consistently, TIMSS has given educational stakeholders a lot of information that may be helpful in their planning for better education (Eklöf et al., 2014).

Our review of TIMSS reports, particularly for the $8^{\text {th }}$ grade level, reveals that South East Asian countries, including Japan, China, South Korea, Hong Kong and Singapore have obtained almost the best ranking in mathematic content domain which is mentioned in TIMSS 1999, 2003, 2007 and 2011 (Table 1). This significant difference in mathematics achievement among these countries may signify the appropriateness and richness of their content of mathematics of the secondary schools. However, our review of literature revealed that by far, there has been little to no study investigating whether the outstanding performance of South East Asian countries such as Singapore can be because of the appropriateness of mathematics textbooks content in these countries. For example, Soh (2000) showed that Singaporean mathematics students in the $8^{\text {th }}$ grade performed well because of the home condition and strong social motivation to do well in general and in Mathematics in particular across the country. Yet, no study tried to link the content of mathematics textbooks to the outstanding achievement in TIMSS among these countries.

Considering Singapore as one of the best, if not the most, successful countries in mathematics achievement in TIMSS history, the present study aims to investigate the content of mathematics textbooks of the secondary schools in this country. Consistently, the present study provides a detailed overview of mathematics curriculum in Singapore, and the content of mathematics textbooks, especially in $8^{\text {th }}$ grade, to reveal the possible reasons for such a success of Singapore in mathematics achievement in TIMSS.

Table 1. TIMSS ranking in $8^{\text {th }}$ grade based for some Southeast Asia countries

\begin{tabular}{lllllllll}
\hline Country & \multicolumn{3}{l}{ Score of participants } & \multicolumn{4}{c}{ Ranking of participants } \\
\hline & 1999 & 2003 & 2007 & 2011 & 1999 & 2003 & 2007 & 2011 \\
\hline Japan & 579 & 570 & 570 & 570 & 5 & 5 & 5 & 5 \\
South Korea & 587 & 589 & 597 & 613 & 2 & 2 & 2 & 1 \\
Chinese Taipei & 585 & 585 & 598 & 609 & 3 & 4 & 1 & 3 \\
Singapore & 604 & 605 & 593 & 611 & 1 & 1 & 3 & 2 \\
Hong Kong & 582 & 586 & 572 & 586 & 4 & 3 & 4 & 4 \\
Malaysia & 519 & 508 & 474 & 440 & 16 & 10 & 20 & 26 \\
International average & 487 & 466 & 500 & 467 & - & - & - & - \\
\hline
\end{tabular}

\section{Singaporean Students' Achievement in Mathematics Content Domains of TIMSS}

TIMSS mathematics assessment for mathematics items in the eighth grade includes four content domains of Numbers, Algebra, Geometry, and Data and Chance (Statistics and Probability). Indeed, comparing the students' achievement in different contents will better mathematics achievement for each country explain. For achieving this aim, it is necessary to compare and analyze the content of the mathematics textbooks in Singapore (Secondary 2) with content domains of TIMSS. Consistently, Table 2 compares the Singaporean students' achievements in various content domains (in TIMSS). Table 2 shows that Singapore has always been among the top four best performing countries (in terms of students' achievement) for content domains, particularly the Number content domain. A quick look at Table 2 also reveals that Singapore has successfully maintained its mathematics performance for the content domains all throughout 2003 to 2011. 
Table 2. Singaporean students' achievements in content domains in TIMSS 2003, 2007, and 2011

\begin{tabular}{llllllllllllll}
\hline $\begin{array}{l}\text { TIMSS } \\
\text { content } \\
\text { domains }\end{array}$ & \multicolumn{1}{l}{ TIMSS 2003} & \multicolumn{1}{c}{ TIMSS 2007 } & \multicolumn{1}{c}{ TIMSS 2011 } \\
\hline & AVS* & Ranking & INA & HIT & VAS & Ranking & INA & HIT & AVS & Ranking & INA & HIT \\
\hline Number & 618 & $1^{\text {st }}$ & 467 & 618 & 597 & $1^{\text {st }}$ & 500 & 597 & 611 & $1^{\text {st }}$ & N/A & 618 \\
Algebra & 590 & $1^{\text {st }}$ & 467 & 597 & 579 & $3^{\text {rd }}$ & 500 & 617 & 616 & $3^{\text {rd }}$ & N/A & 617 \\
Geometry & 580 & $4^{\text {th }}$ & 467 & 598 & 578 & $3^{\text {rd }}$ & 500 & 592 & 609 & $3^{\text {rd }}$ & N/A & 612 \\
$\begin{array}{l}\text { Data } \\
\text { Chance }\end{array}$ & $\&$ & 579 & $1^{\text {st }}$ & 467 & 579 & 574 & $2^{\text {nd }}$ & 500 & 580 & 607 & $2^{\text {nd }}$ & N/A & 616 \\
\hline
\end{tabular}

Note: There is no average achievement in 2011 based on its report (TIMSS 2011, p. 144). Average scale Score, AVS, International average; INA, HIT; Highest score. N/A: not available.

\section{Methodology}

This research is a qualitative case study and the instrument used is document analysis. Therefore, the document analysis performed in this study includes the comparison between the content of mathematics textbook $\left(8^{\text {th }}\right.$ and $7^{\text {th }}$ grade) of Singapore with content domain of TIMSS.

\section{Findings and Discussion}

\subsection{Mathematics Curriculum in Singapore}

According to Soh (2008), from the early 1960s the system of education in Singapore has undertaken many changes. These changes reflect the improvements of the country, the precedence of the education system, and the desire of the people. In 1965, Singapore achieved independence. The priority was to give every child a location in school. There was little attempt to further differentiate the mathematics curriculum, whereas, there were optional syllabi at the higher grades. In the 1980 s, the economy was mainly determined by manufacturing. The ability and productivity of the labor force were significant. With at least 10 years of common education, the system of education obliged itself to providing every student an opportunity of learning. Afterwards, mathematics was obligatory in secondary schools.

In 1990's, education system in Singapore recognized that response to the globalization needs, knowledge of information, technology and economy. Three initiatives were commenced: National Education, Thinking Skills, and the use of Information Technology, to meet the requirements of the people and explore more chances and greater option in the education. Providing the changes is the aim to offer the best education for the students. The phrase to "Teach Less, Learn More" focuses on the quality of teaching and learning, quality of communication between teachers and students, and the quality of school experience in general.

The education in Singapore is organized in a 6-4-2 system, with 6 years of primary school education (Grades 1-6), 4 years of secondary (Grades 7-10) and 2 years of pre-university (Grades 11-12). Nevertheless, there are a few combined schools that offer both primary and secondary education or both secondary and pre-university education at the same site.

There are three courses at the secondary levels. Students are located in the Special/Express, Normal (Academic), or Normal (Technical) courses according to their achievements at the Primary School Leaving Examinations (PSLE). The 4-year express course leads to the General Certificate of Education (GCE) O-level certification. These students normally go on to a pre-university course or polytechnic education. The Normal (Academic) course can be seen as a 4-year course leading to the GCE N-level certification or a 5-year course initiating the O-level certification. The 4-year Normal (Technical) course is aimed to prepare students for technical and service-adjusted courses at the institutes of technical education. It, in addition, causes the GCE N-level certification (Soh, 2008). On the whole, nearly 20 to $25 \%$ of each cohort of students ultimately carries on to the universities. Nearly $60 \%$ of every group of students are in the Express course, $25 \%$ in the Normal (Academic) course, and $15 \%$ in the Normal (Technical) course. A mere curriculum framework is employed constantly all through the different levels, differencing merely in the facts at each level but contributing general stress all through the levels. The structure presents a high level perspective of the significant components of the mathematics curriculum and serves as a structure to direct the function of and helpful mathematics program in schools. Teachers are familiar with the structure and it has become a suitable means to communicate and 
examine the mathematics curriculum (Ministry of Education: Curriculum Planning and Development Division, 2004, 2006a, 2006b).

At the midpoint of the structure is the focal of their mathematics curriculum, which is mathematical problem-solving. It refers to the intellectual and resourceful use of mathematics as a means for solving problems. The use of mathematics as a means and language to describe, cause, formulate, solve and assess a problem is underlined in different shades and types inside the mathematic curriculum.

There are five interconnected divisions that preserve the accomplishment of mathematical problem-solving skills. Students need getting a general range of mathematical thoughts and skills, and signifying considerate and proficiency in these aspects. Common procedures, such as making connections, reasoning, communication, and heuristics and thinking skills are also a part of the learning in mathematics. Moreover, meta-cognitive insight and control of one's consideration procedures are important skills required for a good problem solver. The affective domain should not be neglected. Educating a positive function towards the mathematics will foster attention and perseverance in learning and doing mathematics.

The structure of mathematics curriculum has been reorganized to reproduce changing stresses and requirements. Particulars have been added to the framework as it was first progressed in the 1980s. The framework was last reorganized in 2003. For instance, in 2001, the framework contained thinking skills as a division of the novel plan revealed earlier. In 2003, reacting to global movements and stress on knowledge skills, the significance of communication and making connections were considered more important in the framework. The final framework which is current used is illustrated as Figure 1.

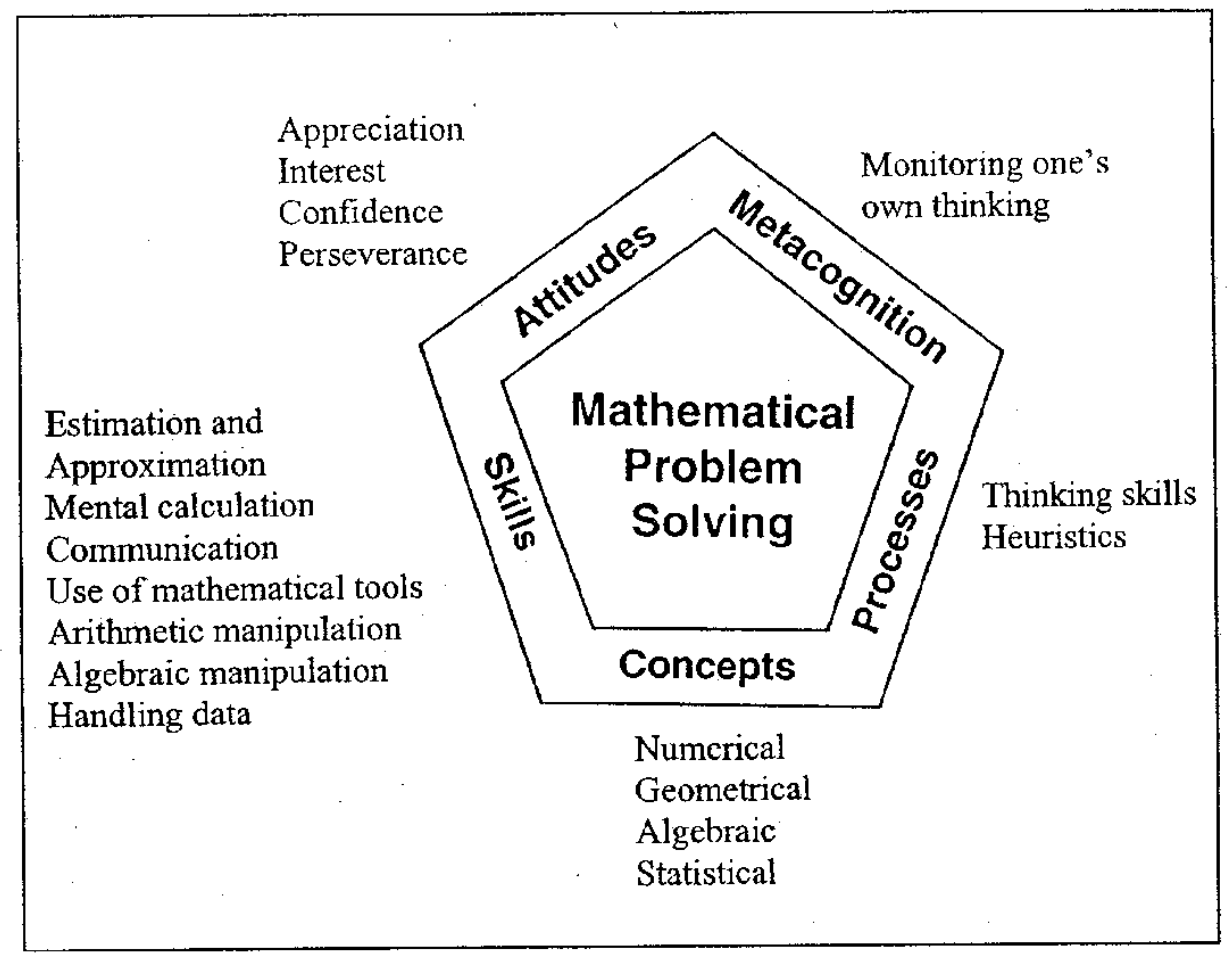

Figure 1. Mathematics curriculum frameworks

Students keep on learning mathematics all through the secondary school years. This means that every student would have up to 10 years of mathematics education. Nevertheless, not all students are expected to learn the similar quantity of mathematics; much relies on the aptitude and interest of the students. There are greater specifications within the curriculum at the secondary levels.

There are three dissimilar mathematics syllabi offering to the students in the three courses. Besides the main mathematics syllabi, students from the express and normal (Academic) courses who are interested in mathematical are provided with an extra mathematics subject. This additional mathematics subject is presented 
from secondary 3 (Grade 9) and plans to organize students for additional studies in mathematics or regulations where more mathematics is necessary. The additional subject contains preliminary topics in calculus. About $60 \%$ of the secondary students choose for the additional mathematics course.

The mathematics syllabus for the normal (Academics) course is planned as a division of a syllabus for the express course. It is planned with the purpose to offer a slower speed of learning that could merge to the preparation for the GCE O-Level in the fifth year. The core focus of the mathematics syllabus for the normal (Technical) course is practical. It highlights the employ of mathematics in every day requests and prepares students for a technical or service oriented course at the technical organizations.

In general, there are five different syllabi for the three secondary courses- a different mathematics syllabus for each of the three courses and two additional mathematics syllabi for the Express and Normal (Academic) courses. There is flexibility for the more talented students from the Normal (Academic) to take the mathematics syllabus in the Express course at the end of the fourth year in place of the fifth, and for the Normal (Technical) to take the mathematics syllabus for the Normal (Academic) course. This difference in the pace of learning adds to the alternatives accessible to students (Soh, 2008).

\section{$4.28^{\text {th }}$ Grades Mathematics Textbooks Content in Singapore}

In Singapore two kinds of books are taught in eighth grade. The first one is entitled "New Mathematics Counts for Secondary 2" (NMC 2), 2nd edition, Normal (Academic), including eight chapters in 340 pages, and the second one is entitled "New Syllabus Mathematics 2" (NSM 2), $6^{\text {th }}$ edition including 12 chapters in 399 pages. We should mention that, some items in TIMSS were selected from contents of textbook in $7^{\text {th }}$ grade. Thus, (NMC 1) and (NSM 1) in Singapore were analyzed as well. Since some of the questions in TIMSS are not limited to eighth grade textbooks and deals with the content of textbook in seventh grade (Secondary 1), therefore, the researcher has also studied on seventh grade (Secondary 1).

In general, NMC 2 syllabuses contain eight chapters including; i) Algebraic Expansions and Factorizations ii) Algebraic Fractions, Equations and Inequalities iii) Cartesian Coordinates and Linear Graphs iv) Proportions and Map Scales v) Simultaneous Linear Equations vi) Triangles, Polygons and Congruence vii) Mensuration and viii) Statistics and Simple Probability. In addition, "New Mathematics Counts for Secondary 1" (NMC 1) syllabuses contain eight chapters including: i) Numbers, Factors and Multiples ii) Rational Numbers and Estimations iii) Percentages iv) Algebraic Expressions and Manipulation v) Ratio ,Rate and Speed vi) basic Geometry vii) Menstruation of Plans and Solids viii) Statistical Representations.

The teaching material for NMC 2 and NMC 1 is discussed in this section in detail. Each chapter opener starts with a text regarding an interesting story or examples related to the topic of the lesson. The textbook contains some interesting information to attract the students' attention as introduction to the main content of the chapter. Moreover, learning targets of the chapter's content is briefly introduced in the chapter opener under the title named: "Discover!" The content of each chapter of textbook is discussed in detail as follows.

Every chapter has a title illustrating the main concept which is divided into a few subtitles. The lesson starts with a brief verbal explanation followed by examples given in the form of graphs and pictures. Another example plus the solution under the name "Worked Examples" and some exercises and time-out activity is given after this description. Every subtitle continues with examples related to the issues they discuss. Worked examples reinforce mathematical concepts through step-by-step guidance. They also show how solutions can be presented. At the end of each subtitle section, some exercises are given in the form of "time-out activity" containing activities which engage students and make the learning process more enjoyable. Some of the activities found here incorporate the use of Information Technology (by introducing related website), Thinking Skills, National Education messages or Journal Writing tasks. Another part here is "Note". Note provides students with the necessary pointers to enhance their understanding of concepts. This feature is also used to recall prerequisite concepts. Moreover, Journal Writing tasks comprise questions that encourage students to reflect, discuss or explain application of concepts. Students are also encouraged to write their explanations or thought processes in a journal, helping them to clarify their understanding. The length of the contents presented under each subtitle section varies, depending on the importance and complexity of the discussed issue.

Each chapter ends with a Summary section which serves as a recap and revision of the main concepts covered in the chapter. It included "Enrichment Math's", "10 Minutes Concept Check", "Review paper", and "Revision paper". For example, "10 Minutes Concept Check" helps students diagnose their understanding of each section within a chapter. Each question has been labeled with the corresponding section number to allow students to identify their areas of weakness. Also, "Revision Paper" serves as an overall revision to help students get prepared for examination. "Revision Paper" provided at the end of each chapter for consolidated practice, these 
questions are grouped into three different sections in increasing order of difficulty. In addition, "Enrichment Math's" containing multi-faced activities that allow students to investigate mathematical ideas or explore practical applications, this section provides excellent opportunities for class discussions.

On the other hand, NSM 2 syllabuses include 12 chapters namely 1) Congruence and Similarity; 2) Direct and Inverse Proportions; 3) Expansion and Factorization of Algebraic Expressions; 4) Algebraic Manipulation and Formulae; 5) Simultaneous Linear Equations; 6) Pythagoras' Theorem; 7) Volume and Surface Area; 8) Graphs of Linear Equations in Two Unknowns; 9) Graphs of Quadratic Equations; 10) Set Language and Notation; 11) Statistics and 12) Probability. This book also includes four Revision Exercises. Moreover, NSM 1 syllabuses contain 16 chapters, including: 1) Factors and Multiples; 2) Integers; 3) Rational numbers; 4) Terminating recurring Decimals; Estimation and Approximation; 5) Fundamental Algebra; 6) Number Sequences; 7) Algebraic Equations and Simple inequalities; 8) Perimeter and Area of Simple Geometrical Figures; 9) Volume and surface Area; 10) Ratio, Rate and Speed; 11) Percentages; 12) Function and Graphs; 13) Statistics; 14) Basic Geometrical Concepts and Properties; 15) Angle Properties of Polygons and 16) Geometrical Constructions. Likewise, NSM also has four Revision Exercises.

There are some positive and interesting contents in both NMS 2 and NMS 1 which lead to increasing the pupils' motivation. For example, chapter 1 of NMS 2 entitled "Congruence and Similarity", there are some photos and texts which make pupils to be motivated sufficiently to find the solution of the raised real problem after studying and learning the concept and congruency and its applications. It means that the focus is on problem solving and discovery learning in this textbook and it is one of the points of its strength. Also, there is a part entitled "Just for Fun" that can be effective for learning of students such as the factorization example in page 100, NMS 2 or associative law example in page 46, NSM 1. Moreover, there is a part entitled "Thinking Time" which asks a question and wants us to think about and then find the answer in time like page 58, NSM 2 or page 91, NSM 1. "Review Examples" parts in each chapter also make stronger confirmation for its learning by another examples and solutions like the example in page 171, NSM 2.

In addition, there is a part entitled "For your Information" that makes pupils familiar with some real fact of mathematics around world. It makes mathematics interesting for pupils, for instance, on page 92, NSM 1, which explains about "Father of Algebra" or the Muslim mathematician, Al-Khwarizmi. "Explorations" part is also important to make pupils familiar with applying mathematics in real life, such as the one in page 170, NSM 2 that assists students to solve a pair of simultaneous equations involving two unknowns. Overall, the method of presenting the content in this textbook was in both NSM2 and NSM 2 are considerably similar.

Finally, it should be mentioned that mathematics books in Singapore include some interesting and detailed mathematics examples that assist students better understand important and basic mathematic concepts. These examples, which usually root in natural examples, increase the students' interest in mathematics. For example, in page 83 of NMC1 there is an examples which describe the Fibonacci Sequences $(1,1,2,3,5,8,11, \ldots)$ in the form of increasing population of rabbits. In this regard, there is also a graph in page 115 of NSM 1 that visually explains this subject. In addition, there is an example in page 155 of NMC 1 that introduces the Golden Ratio of

$\frac{X}{Y}=\frac{1+\sqrt{5}}{2}$. This ration, which has had many implications within the history of art and engineering, enhances the students' interest in mathematics.

The Content of mathematic textbooks in Singapore is investigated by the researcher based on content domains of TIMSS as below (Table 3):

Numbers: In NMC 2 Numbers are not taught, and in NMC 1 around 155 pages in four chapters are devoted to Numbers, hence, total number of 155 pages are devoted to numbers in NMCS 1\&2. In NSM 2, Numbers are not taught as well, but in NSM 1, 88 pages in four chapters are devoted to numbers.

Algebra: In NMC 2 textbook, five chapters including 172 pages are devoted to Algebra topics as Expansions and Factorizations, Fractions, Equations, Inequalities, Cartesian, Coordinates and Linear Graphs, Proportions and Map Scales Simultaneous and Linear Equations, and in NMC 1 one chapter in 35 pages is devoted to Algebra topic as Expressions and Manipulations. Hence, a total number of 207 pages is devoted to Algebra topics in NMC 1 and 2. In NSM 2 six chapters including 190 pages are devoted to Algebra topics as Direct and Inverse Proportions, Expansion and Factorizations of Algebraic Expressions, Manipulation and Formula, Simultaneous Linear Equations, Graphs of Linear Equations in Two Unknowns, and Graphs of Quadratic Equations and in NSM 1, six chapters including 80 pages are devoted to Algebra topics as Fundamental Algebra, Equations and Simple Inequalities, Functions and Graphs. A total number of 270 pages is devoted to Algebraic topics in NSM 1 
Geometry: In NMC 2 textbook, three chapters including 127 pages are devoted to Geometry topics as Cartesian coordination, Triangles, Polygons, and Congruence, Menstruation, and in NMC 1, two chapters including 90 pages are devoted to Geometry topics as Basic Geometry, Menstruation of Plans, and Solids; hence, the total number of 217 pages are devoted to Geometry topics in NMC 1 and 2. Three chapters In NSM 2, including 80 pages are devoted to Geometry topics as Congruence \& Similarity, Pythagoras' Theorem, and Volume and Surface Area, and in NSM 1, six chapters including 137 pages are devoted to Geometry topics as Perimeter and Area of Simple Geometrical Figures, Volume and Surface Area, basic Geometrical Concepts and properties, Angle Properties of Polygons, and Geometrical Constructions. Hence, the total number of 217 pages is devoted to Geometry topics in NSM 1 and 2.

Data and Chance: In NMC 2 textbook, one chapter including 55 pages is devoted to Data (Statistics) and chance (Simple Probability) topics such as data diagrams, Steam-and-leaf Diagram, statistical averages (mean, median, mode of Ungrouped Data), Use and Purpose of Mean, Median and Mode, Mean of Grouped Data, and simple chance (probability) including introduction, Favorable outcomes and Simple Space Simple Probability. In NMC 1 , one chapter including 50 pages is also devoted to statistics topics as collection data, pictogram, Bar graphs, Pie charts, Frequency tables and histogram; hence, the total number of 104 pages is devoted to data and chance in MCS 1 and 2. In NSM 2, 41 Pages are devoted to Data and 26 to Chance. The total number of 67 Pages is devoted to Data and Chance in NSM 2 and NSM 1, 35 pages is devoted to statistics. The total number of the pages in NSM 1 and NSM 2 is 102 pages.

In Singapore $8^{\text {th }}$ grade NMC 2, there is no topic related to Numbers, but there are 145 pages $(46 \%)$ in $7^{\text {th }}$ grade. Also, 124 pages are devoted to Algebra (approximately 40\%), 127 pages devoted to Geometry (approximately $40 \%$ ), and 54 pages to data and chance (approximately 17\%). In Singapore seventh grade NMC 1, 155 pages are devoted to Numbers (approximately 47\%), 35 pages are devoted to Algebra (approximately 10\%), 90 pages devoted to Geometry (approximately 27\%), and 50 pages are devoted to Data (approximately 15\%), Chance is not taught in seventh grade. In Singapore, in NMC textbooks in seventh and eighth grade, the total number of 155 pages (24\%) is devoted to Numbers, 169 pages (26\%) to Algebra, 217 pages (34\%) to Geometry, and 104 pages $(16 \%)$ to Data and Chance. In NSM 2 text book, the same as NMC 2, 192 pages are devoted to Algebra (55\%), 90 pages are devoted to Geometry (25\%), 67 pages are devoted to Data and Chance (19\%), and there is not any topic related to Numbers. Table 4 summarizes the pages devoted to each topic in seventh and eighth grade of Singapore mathematics textbooks and their percentages in comparison with the items in TIMSS.

Table 4. The content of mathematics textbooks in Singapore based on the content domains of TIMSS

\begin{tabular}{|c|c|c|c|c|c|c|c|c|c|c|c|c|c|}
\hline \multirow[t]{3}{*}{$\begin{array}{l}\text { Content } \\
\text { Domains in } \\
\text { Singapore } \\
\text { Mathematics } \\
\text { Textbooks }\end{array}$} & \multicolumn{6}{|c|}{$\begin{array}{l}\text { New Mathematics } \\
\text { Counts } 1 \& 2\end{array}$} & \multicolumn{6}{|c|}{ New Syllabus Mathematics $1 \& 2$} & \multirow[t]{3}{*}{$\begin{array}{c}\text { TIMSS } \\
\text { Items } \\
2007 \& \\
2011\end{array}$} \\
\hline & \multicolumn{2}{|c|}{$\begin{array}{c}\text { New } \\
\text { Mathematics } \\
\text { Counts } 1\end{array}$} & \multicolumn{2}{|c|}{$\begin{array}{c}\text { New } \\
\text { Mathematics } \\
\text { Counts } 2\end{array}$} & \multicolumn{2}{|c|}{ Total } & \multicolumn{2}{|c|}{$\begin{array}{c}\text { New Syllabus } \\
\text { Mathematics } \\
1\end{array}$} & \multicolumn{2}{|c|}{$\begin{array}{c}\text { New Syllabus } \\
\text { Mathematics } \\
2\end{array}$} & \multicolumn{2}{|c|}{ Total } & \\
\hline & pages & $\%$ & pages & $\%$ & pages & $\%$ & pages & $\%$ & pages & $\%$ & pages & $\%$ & \\
\hline Numbers & 145 & 46 & 0 & 0 & 145 & 23 & 152 & 38 & 0 & 0 & 152 & 20 & $30 \%$ \\
\hline Algebra & 35 & 11 & 172 & 55 & 207 & 33 & 80 & 20 & 190 & 54 & 270 & 36 & $30 \%$ \\
\hline Geometry & 89 & 28 & 86 & 27 & 175 & 28 & 129 & 33 & 93 & 27 & 222 & 30 & $20 \%$ \\
\hline $\begin{array}{l}\text { Data and } \\
\text { Chance } \\
\text { (Statistic and } \\
\text { Probability) }\end{array}$ & 47 & 15 & 55 & 17 & 102 & 16 & 35 & 9 & 66 & 19 & 101 & 14 & $20 \%$ \\
\hline Total & 316 & 100 & 313 & 100 & 629 & 100 & 396 & 100 & 349 & 100 & 745 & 100 & $100 \%$ \\
\hline
\end{tabular}




\section{Conclusion}

Findings of the current research revealed that Singapore has a strong and well-developed curriculum, which has affected the syllabus of textbooks, especially mathematics textbooks. As pointed out earlier, one reason that Singaporean students have an astonishing performance in TIMSS might be considering this issue that the subjects (Number, Algebra, Geometry, and Data \& Chance) which are under concentration in $8^{\text {th }}$ grade and $7^{\text {th }}$ in TIMSS $(1999,2003,2007$, and 2011) have been thoroughly presented as the content of mathematics textbooks (secondary $2 \& 1$ ) in Singapore. The other reason also accounts for having diverse examples which are in fact more than the number of stated exercises within the textbooks on every subject. Therefore, in the current study we found that throughout Singapore's textbooks, worked examples reinforce mathematical concepts through step-by-step guidance both on examples and the solutions. The examples' note provides students with the necessary points to enhance their understanding of concepts. This feature is also used to recall prerequisite concepts. We also observed that quantity and quality of examples in Singaporean textbooks play a key role in learning process and students' achievement. Mathematics textbooks in Singapore benefits from attractive visualization in terms of using a combination of different colors, providing high-quality and well-designed figures (especially in geometry), conditions that increase the students' interest in mathematics.

\subsection{Implications}

We, for the first time, showed that the richness of mathematics textbooks content can lead to a higher achievement in TIMSS and among the content domains of Number, Algebra, Geometry, and Data \& Chance. This evidence from Singapore can enable syllabus designers and even teachers better assist students' mathematics learning and understanding. We consistently suggest some ways to make the students more interested in mathematics and its application in sciences and real life, based on the successful mathematics teaching approaches applied in Singapore. For example, the process of teaching a specific topic in mathematics can start with the history of mathematics and giving a background about every topic before teaching that topic. Moreover, resource materials play an important role in making students interested in mathematics.

Our results may be used by curriculum designers and text book writers. The thorough analysis and comparison of the textbooks from Singapore (Secondary 1 and 2) based on TIMSS content can provide textbook writers and curriculum designers with a deeper insight and ideas to improve the curriculum to facilitate higher achievements in mathematics learning.

Another group which may benefit from this study is mathematics teachers. They can use the findings both directly, through applying and using some of the results and the methods of teaching provided, and indirectly, through using the improved curriculum and textbooks. In particular, teachers are advised to become familiar with content domains of TIMSS given the advantages that TIMSS can offer to teachers. This may lead to higher mathematics proficiency and higher rankings in TIMSS.

\section{References}

Chudgar, A., Luschei, T. F., \& Zhou, Y. (2013). Science and mathematics achievement and the importance of classroom composition: Multicountry analysis using TIMSS 2007. American Journal of Education, 119(2), 295-316. http://dx.doi.org/10.1086/668764

Curriculum Planning and Development Division. (2004). Assessment guide to lower secondary mathematics. Singapore: The Ministry.

Curriculum Planning and Development Division. (2006a). Nurturing every child; flexibility \& diversity in $\begin{array}{lllll}\text { Singapore } & \text { schools. } & \text { Retrieved } & \text { April } & \text { 10, 2012, from }\end{array}$ http://www.moe.gov.sg/education/files/edu-booklet/edu-booklet-english

Curriculum Planning and Development Division. (2006b). Secondary mathematics syllabuses. Singapore: Curriculum Planning and Development Division. Retrieved April 10, 2012, from http://www.moe.gov.sg/education/syllabuses/sciences/files/maths-secondary.pdf

Eklöf, H., Pavešič, B. J., \& Grønmo, L. S. (2014). A Cross-National Comparison of Reported Effort and Mathematics Performance in TIMSS Advanced. Applied Measurement in Education, 27(1), 31-45. http://dx.doi.org/10.1080/08957347.2013.853070

Gonzales, P., Guzman, J. C., \& Jocelyn, L. (2004). Highlights from the trends in international mathematics and science study (TIMSS). Washington DC: U.S. Department of Education.

Guangzhong, C. (1996). A comparative study of attitudes toward mathematics between selected Chinese high school students and U.S. high school students (Unpublished dissertation). The University of Toledo. 
Kawanaka, T. (2000). Comparative case studies of mathematics instruction (Unpublished dissertation). University of California, Los Angeles.

Maasz, J., \& Schloeglmann, W. (2006). New mathematics education research and practice. Rotterdam: Sense Publishers.

Mills, J. D., \& Holloway, C. E. (2013). The development of statistical literacy skills in the eighth grade: Exploring the TIMSS data to evaluate student achievement and teacher characteristics in the United States. Educational Research and Evaluation, 19(4), 323-345. http://dx.doi.org/10.1080/13803611.2013.771110

Ministry of Education, Singapore. (2000). Mathematics syllabus-Lower secondary. Singapore: Curriculum Planning and Development Division.

Ministry of Education, Singapore. (2001). Mathematics syllabus. Singapore: Ministry of Education.

Ministry of Education, Singapore. (2004). Assessment guide to lower secondary mathematics. Singapore: Curriculum Planning and Development Division.

Ministry of Education, Singapore. (2006a). Nurturing every child; flexibility \&diversity in Singapore schools. Retrieved April 10, 2012, from http://www.moe.gov.sg/education/files/edu-booklet/edu-booklet-english

Ministry of Education, Singapore. (2006b). Secondary mathematics syllabuses. Singapore: Curriculum Planning and Development Division.

Ministry of Education, Singapore. (2012). Our mission. Retrieved August 3, 2012, from http://www.moe.gov.sg/about/

Nixon, R. S., \& Barth, K. N. (2014). A Comparison of TIMSS Items Using Cognitive Domains. School Science and Mathematics, 114(2), 65-75. http://dx.doi.org/10.1111/ssm.12054

Soh, C. K. (2008). An overview of mathematics education in Singapore. In Z. Usiskin, \& E. Willmore (Eds.), Mathematics Curriculum in Pacific Rim Countries-China, Japan, Korea, and Singapore (pp. 23-36). Charlotte, NC: Information Age Publishing.

Soh, K. C. (2000). Why Singaporean eighth graders did better among the Asian nations in the TIMSS mathematics: A secondary analysis. The Mathematics Educator, 5(1), 169-179.

TIMSS. (1999). Trends in international mathematics and science study, International Associations for the Evaluation of Educational achievement. Retrieved from http://timssandpirls.bc.edu/timss 1999.html

TIMSS. (2003). Trends in international mathematics and science study, International Associations for the Evaluation of Educational achievement. Retrieved from http://timss.bc.edu/timss2003.html

TIMSS. (2009). Trends in international mathematics and science study, International Associations for the Evaluation of Educational achievement. Retrieved from http://timss.bc.edu/timss2007/intl_reports.html

TIMSS. (2011). Trends in international mathematics and science study, International Associations for the Evaluation of Educational achievement. Retrieved from http://timss.bc.edu/timss2011/

\section{Copyrights}

Copyright for this article is retained by the author(s), with first publication rights granted to the journal.

This is an open-access article distributed under the terms and conditions of the Creative Commons Attribution license (http://creativecommons.org/licenses/by/3.0/). 